International Journal of Health Sciences
Available online at www.sciencescholar.us
Vol. 4 No. 3, December 2020, pages: $39-48$
e-ISSN: 2550-696X, p-ISSN: 2550-6978
https://doi.org/10.29332/ijhs.v4n3.455

\title{
Doula Assistance on Anxiety and Duration of Giving Birth in Normal Mother Giving Birth
}

\begin{abstract}
CrossMark
Putu Ayu Ratna Darmayanti a, Ni Luh Putu Januraheni ${ }^{b}$, Dwi Widyaningsih Nugraeni ${ }^{c}$

Manuscript submitted: 9 July 2020, Manuscript revised: 18 August 2020, Accepted for publication: 27 September 2020

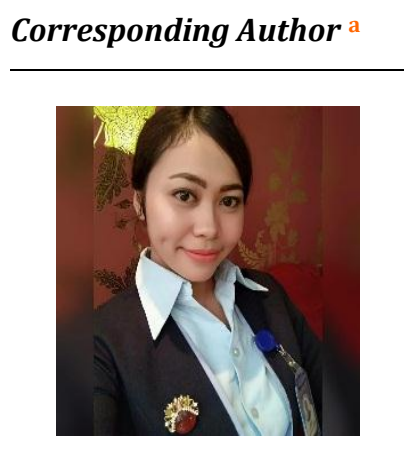

Keywords

anxiety;

delivery assistance;

doula assistance;

doulas:

Abstract

Normal childbirth has a high risk of causing excessive anxiety during the delivery process which can adversely affect the mother and the fetus. Besides, the long labor duration makes women even more anxious and afraid to go through the normal labor phase. However, anxiety and the duration of labor can be minimized and reduced with support and the presence of a doula during normal labor. The benefits of doula assistance during the normal delivery process are also not widely known because it is not commonly implemented in Indonesia. This study aims to prove the effect of doula assistance on anxiety and normal delivery duration. This study is a true experimental design with a Posttest Only with Control Group Design with a total sample size of 62 normal maternal mothers in the delivery room of the TK II Udayana Hospital Denpasar Bali which is divided into two groups, namely the intervention group as many as 31 people given doula assistance and a comparison group of 31 people who only provided support from their husbands. Observations and interviews were carried out immediately after delivery.
\end{abstract}

labor duration;

International Journal of Health Sciences (C) 2020. This is an open access article under the CC BY-NC-ND license (https://creativecommons.org/licenses/by-nc-nd/4.0/).

\section{Contents}

Abstract

1 Introduction

2 Materials and Methods

3 Results and Discussions

4 Conclusion

Acknowledgments

References

a Hospital TK II Udayana Denpasar, Bali Institute of Technology and Health, Indonesia

b Hospital TK II Udayana Denpasar, Bali Institute of Technology and Health, Indonesia

c Hospital TK II Udayana Denpasar, Bali Institute of Technology and Health, Indonesia 


\section{Introduction}

Childbirth is a natural process in the form of expulsion of the product of conception, namely the fetus and placenta that have been terminated through the birth canal or other means, with their help or strength. Childbirth is a very important event in a woman's life. The process of childbirth has a different meaning for every woman, in the absence of experience of childbirth; it will cause excessive anxiety and fear during the labor process. This situation often occurs in women during childbirth. The delivery process is influenced by three factors, namely passenger, power, and passage. The journey of childbirth can occur normally if these three factors are met properly. Besides, other factors affect the delivery process, namely helper and psychological and helper. Women who are undergoing labor will easily feel anxious, fearful, and anxious which results in increased pain during the labor process and can interfere with the delivery process so that it is not smooth or the duration of labor becomes longer. Anxiety is one of the main factors that influence the course of labor (Campbell et al., 2006; Gordon et al., 1999; Nommsen-Rivers et al., 2009). Labor and may result in a less smooth opening. The impact of anxiety can cause pain in labor and cervical dilatation that is not smooth, causing the duration of labor to belong. The active phase of labor should ideally not exceed 10 hours. Besides, poor uterine contractions can inhibit blood circulation from the uterus to the placenta which can affect the fetus.

Pregnant mothers who feel excessive anxiety can result in babies, namely premature babies and even miscarriages. Besides, this condition also affects the mother, namely an increase in temperature, blood pressure, heart rate, the mother becomes tired and loses strength so that it interferes with the delivery path to traffic jams. , such as breech, shoulder dystocia, prolonged or prolonged labor duration due to weak contractions. Labor with a long duration can affect the fetal heart rate so that it experiences tachycardia or bradycardia. Halimatussakdiah (2017), a study in Aceh Indonesia shows that there is a relationship between long labor duration and the baby's condition or the infant's Apgar score ( $p$-value 0.000). Thus, choosing the right action and service strategy can prevent long labor duration and reduce the level of maternal anxiety. During the delivery process, mothers need physical and psychological support to relieve the unstable psychological condition of the mother, the role of husbands, health workers, and doulas. very much needed during the delivery process. This makes the mother calmer, does not feel anxious so that labor can run smoothly, quickly and the duration of labor is shorter. However, if there is a lack of support and no assistance during the delivery process, it can cause various problems. The most common problems that occur in women who are facing childbirth without assistance are increased anxiety, mothers feel helpless, husbands are at risk of not being able to place their support, and increasing the presence of medical action. Therefore, assistance during childbirth is needed by mothers to provide emotional and psychological support to mothers who give birth. Support during childbirth in Indonesia is usually done by midwives because they already have knowledge about childbirth that focuses on psychosocial aspects. But the problem of the number of patients who exceed the number of health workers and time constraints and a large number of documentation tasks prevent midwives from continuously providing support for childbirth. Besides, in Indonesia, childbirth support is often carried out by the husband as the closest family member who can provide attention and comfort (BOlBOl-haGhiGhi et al., 2016; Hayati et al., 2018; Kashanian et al., 2010). However, husbands often do not understand how to provide good and correct childbirth support to reduce excessive anxiety. So, the normal delivery process should be ensured to get labor support from a childbirth companion who can accompany and provide support during the delivery process so that the mother's love care movement can be realized and mothers who give birth do not feel alone in making decisions. Research by Haghighi in Shahroud Iran 2016 shows that support during labor is a key factor in having a good experience during labor. To increase and reduce stress and anxiety levels in women during labor and to overcome labor pain.

The World Health Organization (WHO) has recommended assisting in childbirth that is determined by the wishes and on the choice of the mother. However, the participation of husbands in reproductive health is still low; there are still many husbands who have not been able to show their role during the delivery process. The effect of no assistance during childbirth has an impact on anxiety, resulting in excessive levels of catecholamines resulting in decreased blood flow to the uterus, weakened uterine contractions, decreased 
blood flow to the placenta so that oxygen available to the fetus is reduced and the length of labor duration. Guyton (2007) states that the benefits of childbirth assistance can lead to feelings of pleasure, which will become an impulse to the neurotransmitter to the limbic system which is then transmitted to the amygdala and then to the hypothalamus, causing stimulation of the ventromedial nucleus and the surrounding area which can cause a feeling of calm and ultimately decreased anxiety. With a sense of comfort, the level of catecholamines in the blood will cause smooth muscle to relax and vasodilate blood vessels so that the supply of blood and oxygen to the uterus increases so that the pain that the mother feels is also reduced and speeds up the labor process. Professionals abroad called with a doula is a woman who has been trained and has experience in childbirth as well as assisting mothers and their husbands from the start during labor. Doulas provide physical comfort, emotional support, non-clinical information, birthing positions, and relaxation techniques during labor (Altman et al., 2015; Bayrami, 2011; Morhason-Bello et al., 2008). Doulas are a profession that accompanies labor during labor. The doula ensures that the mother is comfortable during labor, relaxes, and reduces pain during the delivery process. So that mothers who give birth can have an interesting and pleasant experience, seconds of meeting with babies who have been in the womb. The results of the study indicate that doula assistance at delivery can make labor times shorter, the experience of giving birth is satisfying and the mother will be more cooperative during childbirth. According to Kurniawati (2020) in Bojonegoro Regency, the need for doula assistance to pregnant women in the delivery process shows that most mothers need doula assistance during pregnancy and childbirth. Doula assistance increases normal delivery by $50 \%$ and shortens labor duration by $25 \%$. Doulas can provide emotional, physical, and information support about childbirth. However, providing midwifery care to mothers who give birth with doula assistance is not common in Indonesia.

Doula assistance or skilled and professional birth attendant during the normal delivery process is still very rare in Indonesia, especially in Bali. Doula assistance will assist mothers and families during the delivery process. It is hoped that mothers who give birth can go through the labor process without feeling excessive anxiety and a shorter duration of labor so that they are calmer in going through the process of an optimally healthy birth (Chor et al., 2015; Beebe et al., 2007; Singh \& Parmar, 2015). There is still limited research on this doula, especially in Bali, Indonesia and the increasing number of pregnant women who prefer to give birth by Sectio Sesaria (SC) rather than normal delivery because of the feeling of fear and anxiety about the long labor process underlines the need to research this sector (Chen et al., 2012; Gilliland, 2011; Gruber et al., 2013). So that the approach by providing doula assistance during normal delivery can help women giving birth in a healthy, safe, and comfortable birth process. Based on the description of the problem above, the formulation of the problem in this study is how the influence of doula assistance on anxiety and the duration of labor in women with normal delivery. The purpose of this study was to determine the effect of doula assistance on anxiety and the duration of labor in normal delivery mothers at Tk II Udayana Hospital Denpasar.

\section{Materials and Methods}

This study is a True Experimental Design that uses a Posttest Only With Control Group Design which was conducted on 62 mothers who gave birth at Tk II Udayana Hospital Denpasar Bali. The research was conducted from July to August 2020 with the assistance of a Doula as a companion for normal delivery in the intervention group with the criteria of having a certificate of training and experience as a doula. The inclusion criteria in this study were all normal birth mothers who were registered as patients at the Tk. II Udayana Denpasar and willing to be the subject of research. The exclusion criteria for this study were mothers who experienced complications and mothers who gave birth using the Sectio Cecarea (SC) method (Lundgren, 2010; Yates, 2010; Thomas et al., 2017). Subjects were divided into two groups, namely 31 people in the intervention group who were given doula assistance during childbirth and 31 people as the comparison group who were only accompanied by their husbands during the delivery process. During the doula assistance in the intervention group, women giving birth will be taught relaxation techniques, given a massage, and given information related to childbirth and will be accompanied from the beginning of the labor process until the baby is born. Doula mentoring was also supervised by the head midwife at the research location. Assessment of the level of anxiety will be measured in both groups immediately after giving birth while still prioritizing

Darmayanti, P. A. R., Januraheni, N. L. P., \& Nugraeni, D. W. (2020). Doula assistance on anxiety and duration of giving birth in normal mother giving birth. International Journal of Health Sciences, 4(3), 39-48.

https://doi.org/10.29332/ijhs.v4n3.455 
the physical condition and readiness of the research subject in filling out the google form. Meanwhile, the assessment of the duration of labor was observed by midwives on duty in the delivery room.

The minimum sample size required in this study was 62 subjects, calculated with a power of $90 \%$ to detect anxiety levels and labor duration. Relative anxiety reduction was $52 \%$ with a significance level of 0.05 . Before the research began, the subjects first filled out the informed consent on the online google form. An online questionnaire using a google form includes data on maternal demographics, labor processes, anxiety levels, and labor duration. Filling in the google form takes about 15 minutes. Before the research, the doula had also been trained in advance by researchers on how to fill in google forms. Data analysis was performed using the Mann-Whitney test to determine the effect of doula assistance on anxiety levels and delivery duration. This research has obtained a statement of Ethical Appropriateness with Number 04.0049 / KEPITEKES-BALI / VI / 2020 dated 27 July 2020 from the Ethical Commission of the Health Faculty of the Bali Institute of Technology and Health.

\section{Results and Discussions}

From July to August 2020, as many as 137 mothers gave birth to the Udayana Denpasar Bali Kindergarten II Hospital (Figure 1). Of these, 64 subjects were eligible to take part in the study, but 2 subjects were not included in the study because they did not meet the inclusion criteria. Subjects who met the requirements were 62 mothers giving birth, then divided into two groups, namely the intervention group (31 subjects) and the comparison group (31 subjects). As shown in Figure 1. below.

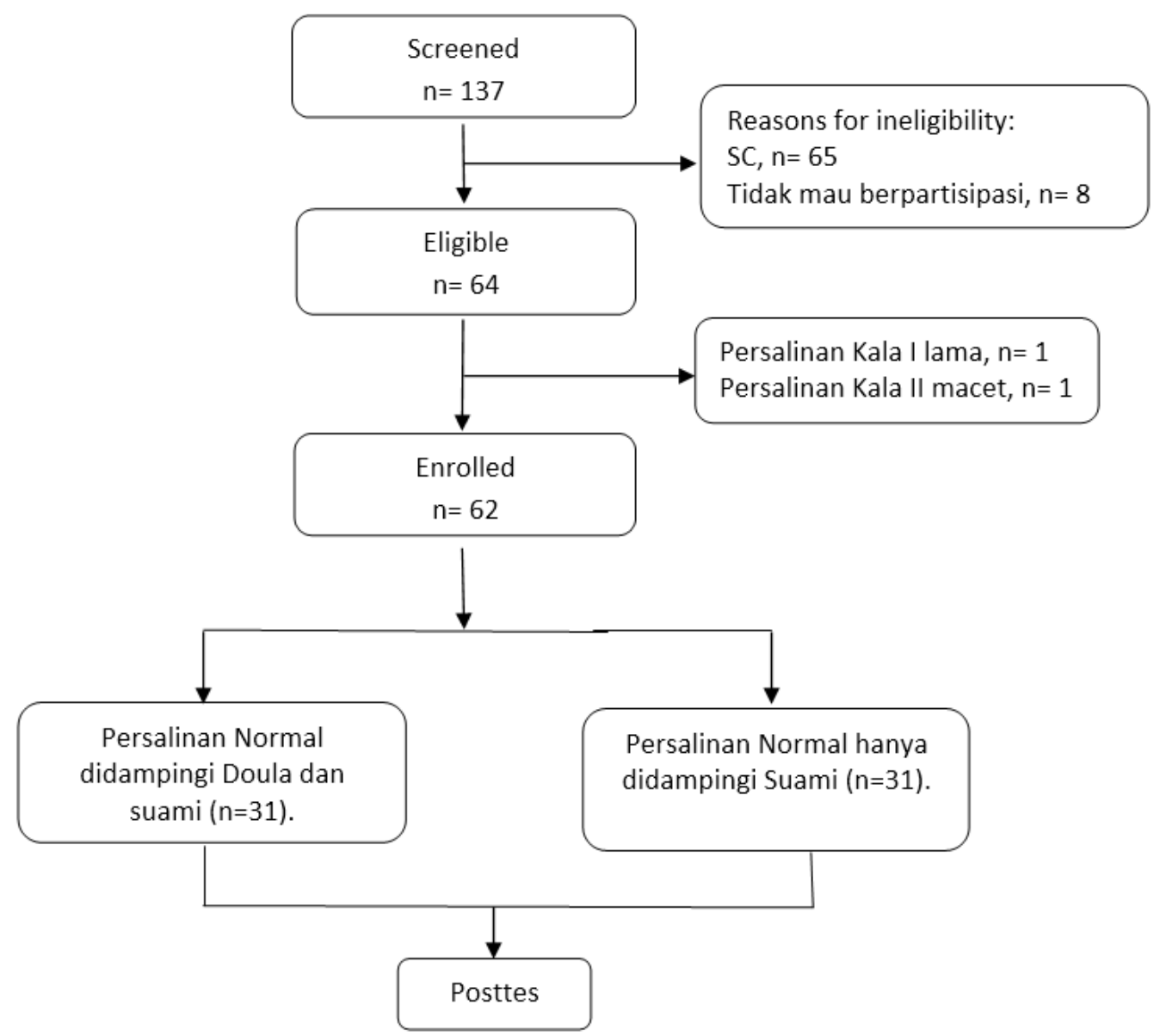

Figure 1. The research subjects 
The characteristics of the subjects of the intervention group and the comparison group in the study are presented in Table 1. below. It can be seen that the characteristics of the subjects are similar (comparable) based on age $(p=0.168)$ and parity $(p=0.391)$. Meanwhile, knowledge $(p=0.001)$ and education $(p=0.001)$ were non-comparable.

Table 1

Comparison of subject characteristics between the two groups

\begin{tabular}{|c|c|c|c|c|c|}
\hline \multirow[t]{2}{*}{ Subject Characteristics } & \multicolumn{2}{|c|}{$\begin{array}{c}\text { Group } \\
\text { Intervention }\end{array}$} & \multicolumn{2}{|c|}{$\begin{array}{c}\text { Group } \\
\text { Comparison }\end{array}$} & \multirow[t]{2}{*}{ P-value } \\
\hline & $\mathrm{n}$ & $\%$ & $\mathrm{n}$ & $\%$ & \\
\hline \multicolumn{6}{|l|}{ Age } \\
\hline$\leq 30$ years & 24 & 77.4 & 19 & 61,2 & \multirow{3}{*}{0.168} \\
\hline$>30$ years & 7 & 22.6 & 12 & 38,8 & \\
\hline \multicolumn{5}{|l|}{ Education } & \\
\hline Junior high school & 5 & 16.1 & 16 & 51.6 & \\
\hline Senior high school & 6 & 19.4 & 5 & 16.1 & \multirow{3}{*}{0.001} \\
\hline Diploma & 5 & 16.1 & 5 & 16.1 & \\
\hline college & 15 & 48.4 & 5 & 16.1 & \\
\hline \multicolumn{6}{|l|}{ Parity (child) } \\
\hline$\leq 2$ & 25 & 80.6 & 26 & 83.9 & \multirow[t]{2}{*}{0.391} \\
\hline$>2$ & 6 & 19.4 & 5 & 16.1 & \\
\hline \multicolumn{6}{|l|}{ Knowledge } \\
\hline less & 8 & 25.8 & 26 & 83.9 & \multirow[t]{2}{*}{0.001} \\
\hline well & 23 & 74.2 & 5 & 16.1 & \\
\hline \multicolumn{6}{|l|}{ Doula Support Needs } \\
\hline needless & 3 & 9.7 & 5 & 16.1 & \multirow[t]{2}{*}{0.001} \\
\hline need & 28 & 90.3 & 26 & 83.9 & \\
\hline Total & 31 & 100.00 & 31 & 100.00 & \\
\hline
\end{tabular}

Table 1 shows that the research subjects in the intervention group were mostly $\leq 30$ years old (77.4\%) and in the comparison group most of them were $\leq 30$ years old $(61.2 \%)$ with the latest education in the intervention group mostly having education up to tertiary institutions (48.4\%) and the comparison group mostly had education up to junior high school $(51.6 \%)$ with $\mathrm{p}=0.001$. The total parity of research subjects in the intervention group mostly had children $\leq$ two people $(80.6 \%)$ and in the comparison group most had $\leq$ two children (83.9\%). Most of the research subjects in the intervention group had good knowledge (74.2\%). Whereas in the comparison group most of the subjects had less knowledge (83.9\%) with a value of $\mathrm{p}=0.001$. Most of the study subjects required the presence of a doula to accompany delivery (83.9\%) in the intervention group and $90.3 \%$ in the comparison group with a value of $\mathrm{p}=0.001$.

Table 2

Comparison between two groups

\begin{tabular}{lccccc}
\hline Subject Characteristics & \multicolumn{2}{c}{$\begin{array}{c}\text { Group } \\
\text { Intervention }\end{array}$} & \multicolumn{2}{c}{$\begin{array}{c}\text { Group } \\
\text { Comparison }\end{array}$} & \multirow{2}{*}{ P-value } \\
\cline { 2 - 5 } & $\mathrm{n}$ & $\%$ & $\mathrm{n}$ & $\%$ & \\
\cline { 2 - 5 } Anxiety Level & 10 & 32.2 & 5 & 16.1 & \\
Light & 15 & 48.4 & 10 & 32.2 & 0.018
\end{tabular}

Darmayanti, P. A. R., Januraheni, N. L. P., \& Nugraeni, D. W. (2020). Doula assistance on anxiety and duration of giving birth in normal mother giving birth. International Journal of Health Sciences, 4(3), 39-48. https://doi.org/10.29332/ijhs.v4n3.455 


\begin{tabular}{lccccc} 
Weight & 6 & 19.4 & 16 & 51.7 & \\
$\begin{array}{l}\text { Duration of Labor } \\
\leq 10 \text { hours }\end{array}$ & 24 & 77.4 & 11 & 35.5 & 0.013 \\
$>10$ hours & 7 & 22.6 & 20 & 64.5 & \\
\hline Total & 31 & 100.00 & 31 & 100.00 & \\
\hline
\end{tabular}

The posttest is carried out immediately after the mother gives birth while still observing the condition and readiness of the subject in answering the google form that has been given to get an assessment of the subject's anxiety level during the labor process. Meanwhile, the assessment of the duration of labor was carried out utilizing observation by the midwife who was in charge of the delivery room immediately after giving birth. The results of the analysis test of the level of anxiety during normal delivery between the two groups experienced a significant difference. Most of the intervention groups experienced a moderate level of anxiety $(48.4 \%)$. Meanwhile, in the comparison group, most of them experienced a level of anxiety with a heavy category $(51.7 \%)$ with a value of $p=0.018$. The results of the analysis test on the duration of delivery showed that most subjects in the intervention group had a labor duration $\leq$ of 10 hours (77.4\%). Meanwhile, most of the subjects in the comparison group had a labor duration of $>10$ hours $(64.5 \%)$ with a value of $p=0.013$. As listed in Table 2 above. The posttest data normality test is used to determine whether the posttest data population is normally distributed or not. The results of the calculation of the normality test analysis are presented in Table 3. and Table 4. below.

Table 3

Normality test of intergroup anxiety levels

\begin{tabular}{ccc}
\hline Statistic test & $\begin{array}{c}\text { Intervention } \\
\text { Group }\end{array}$ & $\begin{array}{c}\text { Comparison } \\
\text { Group }\end{array}$ \\
\hline $\begin{array}{c}\text { Kolmogorv- } \\
\text { Smirnov }\end{array}$ & 0.001 & 0.150 \\
\hline
\end{tabular}

Table 3 shows that the normality test for the level of anxiety in the intervention group is 0.001 smaller than the value $(\alpha=0.05)$. Meanwhile, the level of anxiety in the comparison group is 0.150 greater than the value $(\alpha$ $=0.05)$.

Table 4

Normality test for the intergroup duration of labor

\begin{tabular}{ccc}
\hline Statistic test & $\begin{array}{c}\text { Intervention } \\
\text { Group }\end{array}$ & $\begin{array}{c}\text { Comparison } \\
\text { Group }\end{array}$ \\
\hline $\begin{array}{c}\text { Kolmogorv- } \\
\text { Smirnov }\end{array}$ & 0.001 & 0.152 \\
\hline
\end{tabular}

Table 4 shows that the normality test for the duration of labor in the intervention group is 0.001 smaller than the value $(\alpha=0.05)$. Meanwhile, the duration of delivery in the comparison group was 0.152 greater than the value $(\alpha=0.05)$. Because one of the data was not normally distributed, it was continued with a nonparametric analysis test using the Mann-Whitney test. The results of the Mann-Whitney test can be seen in Table 5. below.

Table 5

Mann-Whitney test calculation results

\begin{tabular}{cccc}
\hline & Mann-Whitney & $\mathrm{Z}$ & $\begin{array}{c}\text { Asymp. Sig. } \\
\text { (2-tailed) }\end{array}$ \\
\hline Anxiety Level & 323.500 & -2.365 & 0.001 \\
\hline $\begin{array}{c}\text { Duration of } \\
\text { Labor }\end{array}$ & 174.000 & -4.625 & 0.001 \\
\hline
\end{tabular}


The Mann-Whitney test on the post-test can show an outline of the effect of doula accompaniment between the two groups after the intervention. Based on Table 5 above, the results of the Mann-Whitney test analysis on the level of anxiety and duration of labor show a significant probability value (0.001), which means that in general there is an effect of doula assistance on reducing anxiety levels and labor duration between the intervention group and the group. comparison.

\section{Discussion}

Midwifery services for mothers who give birth by providing additional services in the form of doula assistance as an effective effort to provide physical, psychological, and emotional support have not been widely applied in Indonesia. This is due to the lack of research on doula assistance in Indonesia. So that many people do not know the positive benefits of the role of doula assistance for maternity mothers. In this study, it shows that the results of the Mann-Whitney test analysis on the level of anxiety are 0.001 where this value is smaller than the significant value $(\alpha=0.05)$, so the probability $<0.05$. So Ho is rejected, which means that there is a significant effect of doula assistance on the level of anxiety between the intervention group and the comparison group. Most of the mothers who gave birth in the intervention group experienced a moderate level of anxiety (48.4\%). Meanwhile, in the comparison group, most of them experienced a level of anxiety with a severe category (51.7\%). The results of other studies indicate that during the delivery process the respondent feels considerable anxiety during labor. However, after giving birth, the group provided with doula assistance showed a greater reduction in anxiety than the group without doula assistance. The delivery process can cause feelings of excessive anxiety, restlessness, and uneasiness, especially if there is no support from husband, family, and health workers. . Providing good support will be useful for women who give birth and children who are born due to the short duration of labor. Mothers who give birth are relaxed, all the muscle layers in the uterus will work together harmoniously so that labor will run smoothly, easily, and comfortably. Assistance during childbirth can increase the confidence of mothers in labor and help adapt to the delivery process, especially reducing anxiety. During painful uterine contractions, doula accompaniment also helps the mother to maintain and control calm, so as not to show anxious and restless reactions. The main role of doula mentoring is to reduce maternal stress and create a calm environment, leading to the release of oxytocin.

The results of the Mann-Whitney test analysis in this study showed that the duration of labor was 0.001 where this value is smaller than the significant value $(\alpha=0.05)$, so the probability $<0.05$. So Ho is rejected, which means that there is a significant effect of doula assistance on the duration of the alliance between the intervention group and the comparison group. Subjects in the intervention group mostly had a labor duration of $\leq 10$ hours $(77.4 \%)$. Whereas subjects in the comparison group mostly had labor duration> 10 hours (64.5\%). Another study in Shahroud Iran showed that there was a shorter duration of labor at the first stage of delivery in the group provided with doula assistance compared to that which was not significantly ( $p$ $<0.001$ ). Besides, the Apgar score of infants showed better results in the group provided with doula assistance compared to those who were not. Based on the results of Thomas's research in 2017 in New York City, it shows that doula support is highly valued and helps mothers in giving birth in expressing their opinions in making decisions related to childbirth. So that doula service is an important component of efforts to reduce anxiety and shorten the duration of delivery. In line with another study in Shiraz Iran in 2015, there was a significant difference between the duration of labor and the level of anxiety of mothers after being given doula assistance compared to those who were not. The provision of doula assistance is a non-pharmacological method that can be recommended to mothers who give birth to increase good results during labor and create a pleasant experience of labor. Research shows that continuous support provided by doulas during labor can reduce the number of cesarean section deliveries. (SC) and reduces the duration of labor. Efforts to provide doula assistance during childbirth should be made for all mothers giving birth.

Doulas have five important roles in pregnancy and childbirth, namely, doulas are special workers who can provide support during pregnancy and childbirth, doulas provide guidance, support and help mothers to optimize care during pregnancy and childbirth, doulas help build mother's confidence and The doula also builds communication between the patient, midwife, and family. Doulas provide emotional support, physical support, delivery preparation, and advocacy, all of which can help reduce anxiety. Providing doula assistance

Darmayanti, P. A. R., Januraheni, N. L. P., \& Nugraeni, D. W. (2020). Doula assistance on anxiety and duration of giving birth in normal mother giving birth. International Journal of Health Sciences, 4(3), 39-48.

https://doi.org/10.29332/ijhs.v4n3.455 
for mothers who give birth is a risk-free effort, and is very effective in reducing the risk of cesarean delivery, forceps, and vacuuming, reducing anxiety during labor and speeding up the duration of labor. Research in Sweden in 2010 shows that doula assistance meets important needs during the delivery process. . The roles of a midwife and a doula are different, however, there are several functions of doula assistance that are very important in midwifery services. When the mother has chosen to be accompanied by a doula during labor, the challenge for the midwife is to provide support and collaborate with the doula and her partner if any. Doula assistance in midwifery services is an additional service that can save labor costs because it can prevent complications during childbirth, improve safety, improve maternal and infant health, reduce anxiety and accelerate the active phase of childbirth, and mothers who give birth get emotional support in going through the labor process. Midwives and doulas must collaborate to optimize the health and safety of mothers in labor and be able to promote doula assistance as an additional service during childbirth. Limitations of this study were only conducted in one hospital in an urban area in Denpasar, Bali with specific subject characteristics and numbers. a small sample so that it cannot be generalized to a wider target population.

\section{Conclusion}

Doula assistance during labor has been shown to significantly reduce anxiety levels and reduce the duration of normal labor. Knowledge was obtained significantly in the intervention group. To reduce the level of anxiety and reduce the duration of normal delivery, doula assistance during normal delivery is necessary so that it can provide a feeling of security and comfort to the mother to achieve maternal love care.

\section{Acknowledgments}

Researchers would like to thank Doula, all midwives at the TK II Udayana Denpasar, and subjects who have participated in this research. 


\section{References}

Altman, M., Sandström, A., Petersson, G., Frisell, T., Cnattingius, S., \& Stephansson, O. (2015). Prolonged second stage of labor is associated with low Apgar score. European journal of epidemiology, 30(11), 1209-1215. https://doi.org/10.1007/s10654-015-0043-4

Bayrami, R. V. Z. (2011). Nulliparous women experience the pain of normal delivery, a qualitative study. J Tabriz Med Uni, 33(3), 9-14.

Beebe, K. R., Lee, K. A., Carrieri-Kohlman, V., \& Humphreys, J. (2007). The effects of childbirth self-efficacy and anxiety during pregnancy on prehospitalization labor. Journal of Obstetric, Gynecologic \& Neonatal Nursing, 36(5), 410-418. https://doi.org/10.1111/j.1552-6909.2007.00170.x

BOlBOl-haGhiGhi, N., MaSOuMi, S. Z., \& KaZeMi, F. (2016). Effect of continued support of midwifery students in labour on the childbirth and labour consequences: a randomized controlled clinical trial. Journal of clinical and diagnostic research: JCDR, 10(9), QC14. https://dx.doi.org/10.7860\%2FJCDR\%2F2016\%2F19947.8495

Campbell, D. A., Lake, M. F., Falk, M., \& Backstrand, J. R. (2006). A randomized control trial of continuous support in labor by a lay doula. Journal of Obstetric, Gynecologic \& Neonatal Nursing, 35(4), 456-464. https://doi.org/10.1111/j.1552-6909.2006.00067.x

Chen, C. C., Chung, U. L., Lee, J. F., Hwang, K. S., Wu, G. J., \& Chang, Y. C. (2012). Preliminary study on the need for birth doulas among pregnant women in Northern Taiwan. Journal of Medical Sciences, 32(5), 225-231.

Chor, J., Hill, B., Martins, S., Mistretta, S., Patel, A., \& Gilliam, M. (2015). Doula support during first-trimester surgical abortion: a randomized controlled trial. American journal of obstetrics and gynecology, 212(1), 45e1. https://doi.org/10.1016/j.ajog.2014.06.052

Gilliland, A. L. (2011). After praise and encouragement: Emotional support strategies used by birth doulas in the USA and Canada. Midwifery, 27(4), 525-531. https://doi.org/10.1016/j.midw.2010.04.006

Gordon, N. P., Walton, D., McAdam, E., Derman, J., Gallitero, G., \& Garrett, L. (1999). Effects of providing hospital-based doulas in health maintenance organization hospitals. Obstetrics \& Gynecology, 93(3), 422426. https://doi.org/10.1016/S0029-7844(98)00430-X

Gruber, K. J., Cupito, S. H., \& Dobson, C. F. (2013). Impact of doulas on healthy birth outcomes. The Journal of perinatal education, 22(1), 49-58. https://doi.org/10.1891/0730-0832.22.1.49

Guyton A.C. \& J.E. Hall. (2007). Textbook of Medical Physiology. Edition 9. Jakarta: EGC. 80-81 p.

Halimatussakdiah. (2017). The duration of labor for the first and second stages of multiparous mothers with Apgar Score for newborns. Journal of Action: Aceh Nutrition Journal, May 2017; 2(1), 6-12.

Hayati, F., Herman, R. B., \& Agus, M. (2018). Perbedaan Tingkat Kecemasan Ibu Bersalin di Puskesmas dengan di Bidan Praktik Mandiri dan Hubungannya dengan Lama Persalinan. Jurnal Kesehatan Andalas, 6(3), 564571.

Kashanian, M., Javadi, F., \& Haghighi, M. M. (2010). Effect of continuous support during labor on duration of labor and rate of cesarean delivery. International Journal of Gynecology \& Obstetrics, 109(3), 198-200. https://doi.org/10.1016/j.ijgo.2009.11.028

Kurniawati FR. (2020). Analysis of Knowledge of Pregnant Women with Doula Needs in the Delivery Process at BPS Bojonegoro Regency. MAKIA Journal of Health Sciences, 10(1), 37-40.

Lundgren, I. (2010). Swedish women's experiences of doula support during childbirth. Midwifery, 26(2), 173180. https://doi.org/10.1016/j.midw.2008.05.002

Morhason-Bello, I. O., Olayemi, O., Ojengbede, O. A., Adedokun, B. O., Okuyemi, O. O., \& Orji, B. (2008). Attitude and preferences of Nigerian antenatal women to social support during labour. Journal of Biosocial Science, 40(4), 553.

Nommsen-Rivers, L. A., Mastergeorge, A. M., Hansen, R. L., Cullum, A. S., \& Dewey, K. G. (2009). Doula care, early breastfeeding outcomes, and breastfeeding status at 6 weeks postpartum among low-income primiparae.Journal of Obstetric, Gynecologic \& Neonatal Nursing, 38(2), 157-173. https://doi.org/10.1111/j.1552-6909.2009.01005.x

Singh, A., \& Parmar, D. S. (2015). A comparative study of competitive anxiety between basketball and volleyball players. International research journal of management, IT and social sciences, 2(1), 1-4. Sjaifullah, A. (2019). An analysis of EFL students' anxiety factors in speaking. International research journal of engineering, IT \& scientific research, 5(3), 43-48.

Darmayanti, P. A. R., Januraheni, N. L. P., \& Nugraeni, D. W. (2020). Doula assistance on anxiety and duration of giving birth in normal mother giving birth. International Journal of Health Sciences, 4(3), 39-48.

https://doi.org/10.29332/ijhs.v4n3.455 
Thomas, M. P., Ammann, G., Brazier, E., Noyes, P., \& Maybank, A. (2017). Doula services within a healthy start program: increasing access for an underserved population. Maternal and child health journal, 21(1), 59-64. https://doi.org/10.1007/s10995-017-2402-0

World Health Organization. WHO Indonesia. Program: Reproductive Health and Making Pregnancy Safer. Country Situation. www.ino.searo.wh

Yates, S. (2010). Pregnancy and Childbirth E-Book: A holistic approach to massage and bodywork. Elsevier Health Sciences.

\section{Biography of Authors}

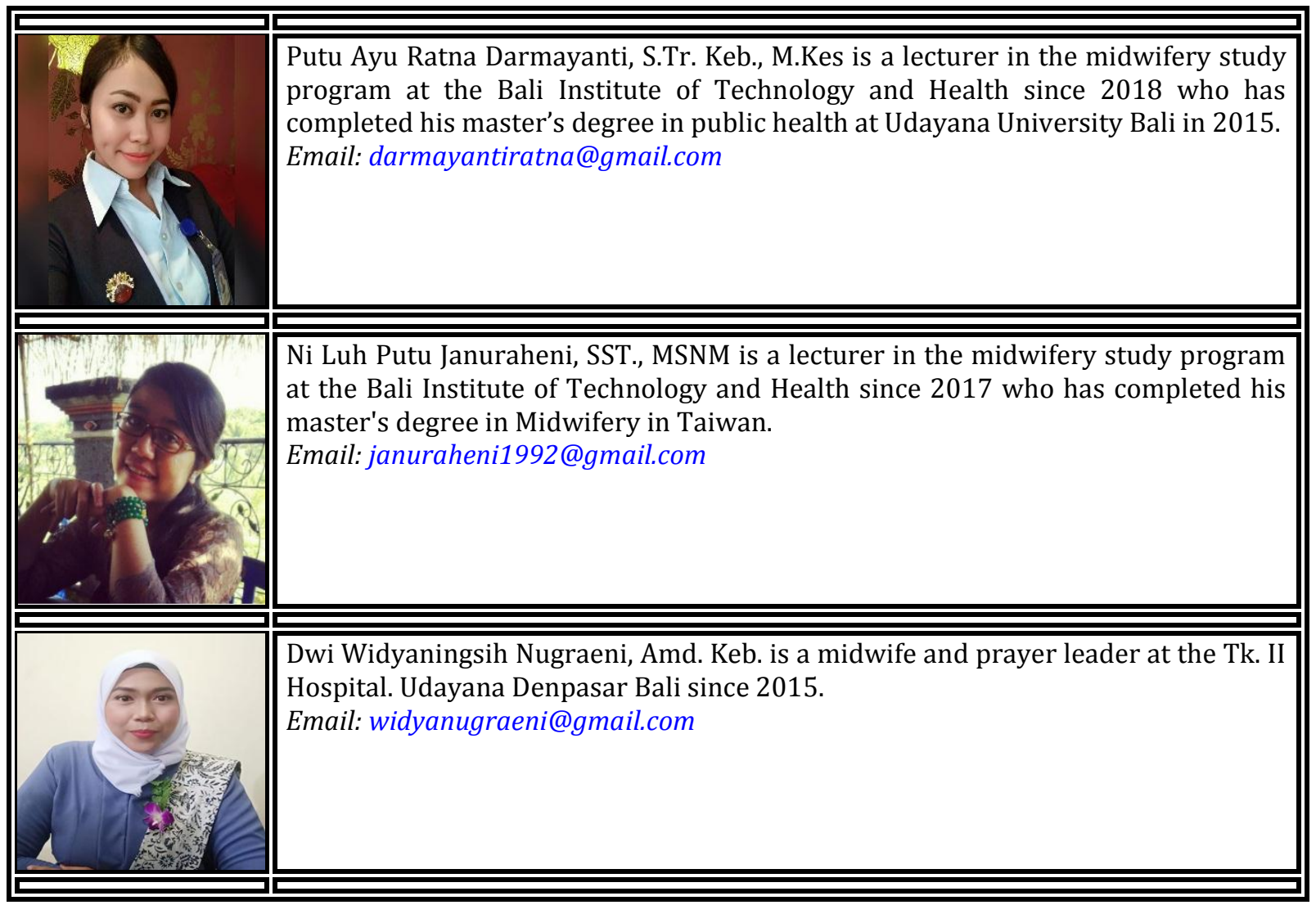

